\title{
Erratum to: Working memory, reasoning, and expertise in medicine-insights into their relationship using functional neuroimaging
}

\author{
Pam Hruska $^{1}$ - Olav Krigolson ${ }^{2} \cdot$ Sylvain Coderre $^{3}$ • \\ Kevin McLaughlin ${ }^{3}$ - Filomeno Cortese ${ }^{4}$ - Christopher Doig ${ }^{5}$. \\ Tanya Beran $^{1} \cdot$ Bruce Wright $^{6} \cdot$ Kent G. Hecker $^{1,7}$
}

\section{Erratum to: Adv in Health Sci Educ (2016) 21:935-952 DOI 10.1007/s10459-015-9649-2}

In order to more accurately reflect the 3D coordinates listed within this article, the column headings should be changed from "MNI coordinates" to "vox coordinates" in Table 1 (p. 943), Table 2 (p. 944), and Table 4 (p. 946). If you would like the MNI coordinates for the Tables, please contact Dr. Kent Hecker.

The online version of the original article can be found under doi:10.1007/s10459-015-9649-2.

\section{Kent G. Hecker}

kghecker@ucalgary.ca

1 Department of Community Health Sciences, Cumming School of Medicine, University of Calgary, Calgary, AB, Canada

2 Neuroscience Program, Centre for Biomedical Research, and School of Exercise Science, Physical, and Health Education, University of Victoria, Victoria, BC, Canada

3 Undergraduate Medical Education, Cumming School of Medicine, University of Calgary, Calgary, $\mathrm{AB}$, Canada

4 Seaman Family MR Research Centre, Hotchkiss Brain Institute, University of Calgary, Calgary, AB, Canada

5 Department of Critical Care Medicine, Cumming School of Medicine, University of Calgary, Calgary, AB, Canada

6 Division of Medical Sciences, University of Victoria, Victoria, BC, Canada

7 Department of Veterinary Clinical and Diagnostic Sciences, Faculty of Veterinary Medicine, University of Calgary, Calgary, AB, Canada 